УДК 621.315 .592

\title{
Источники спонтанного излучения на основе арсенида индия (обзор: десять лет спустя)
}

\author{
(C) С.А. Карандашев ${ }^{1}$, Б.А. Матвеев ${ }^{1}$, М.А. Ременный ${ }^{1,2}$ \\ ${ }^{1}$ Физико-технический институт им. А.Ф. Иоффре Российской академии наук, \\ 194021 Санкт-Петербург, Россия \\ 2 ООО „ИофрфеЛЕД“, \\ 194064 Санкт-Петербург, Россия \\ E-mail: ioffeled@mail.ru
}

(Получена 12 декабря 2017 г. Принята к печати 16 апреля 2018 г.)

\begin{abstract}
Приводится обзор результатов, полученных при исследовании светодиодов на основе гетероструктур c активной областью из InAs, выращенных методами жидкофазной эпитаксии и газофазной эпитаксии из металлоорганических соединений, за последние 10 лет. Проводится анализ картины ближнего поля, ватт-амперных, вольт-амперных характеристик и квантового выхода светодиодов, имеющих конструкцию с точечным контактом и флип-чип, в широком диапазоне температур.
\end{abstract}

DOI: 10.21883/FTP.2019.02.47090.8799

\section{1. Введение}

Оптоэлектронные компоненты, работающие в спектральном диапазоне, соответствующем первому окну прозрачности атмосферы (длины волн $\lambda=3-5$ мкм), широко востребованы, поскольку в этом спектральном диапазоне для них открывается множество важных практических приложений, таких как газовый анализ [1,2], пирометрия [3] и контроль нанотехнологических процессов [4]. Для длин волн вблизи полосы поглощения, обусловленного колебаниями связи $\mathrm{C}-\mathrm{H}(\lambda=3.4$ мкм фундаментальная полоса поглощения углеводородов), наиболее часто упоминаемым в литературе материалом для создания активной области светодиодов (СД), работающих при комнатной температуре, является арсенид индия - прямозонный полупроводник с подходящим для этого значением ширины запрещенной зоны $E_{g}$. „Второе дыхание“ источников спонтанного излучения на основе InAs открылось после отработки технологии получения СД на основе двойных (ДГС) [5] и одиночных (ОГС) гетероструктур [6] InAsSbP/InAs, до настоящего времени доминирующих в списке объектов исследования в научных и производственных организациях. Твердый раствор InAsSbP, изопериодный c InAs, может иметь значение ширины запрещенной зоны вплоть до 0.9 эВ [7], что обусловливает возможность локализации инжектированных носителей заряда в активной области из InAs и вывод излучения через InAsSbP в указанных выше гетероструктурах (ГС).

Ранее мы уже проводили анализ состояния разработок и применения источников спонтанного излучения на основе ГC с активным слоем из InAs [8]; задачей данной работы является анализ результатов исследования таких источников и промышленных применений, а также методов повышения их эффективности, появившихся за 10 лет, прошедших после опубликования предыдущего обзора.

\section{2. Рекомбинация носителей заряда на гетерограницах и в объеме структур InAs/InAsSbP}

В прошедшее десятилетие интерес исследователей, как и в предшествующий период, концентрировался в основном на ГС, содержащих слои твердого раствора InAsSbP, выращенных методом жидкофазной эпитаксии (ЖФЭ) [9-22] или методом газофазной эпитаксии из металлоорганических соединений (МОГФЭ) [23-30] на изопериодных к ним подложках InAs. Это позволяло coздавать структуры с выводом электролюминесцентного излучения как через широкозонный слой InAsSbP, так и через подложку InAs $n$-типа проводимости. В последнем случае важную роль приобретает выбор степени легирования подложки, который можно проводить, например, исходя из степени вырождения электронов в зоне проводимости и спектров поглощения для производимых отечественной промышленностью сильно легированных монокристаллических подложек из $n$-InAs, приведенных B [31].

Гетеропереход InAsSbP/InAs чаще всего относят к гетеропереходу II типа; в таблице приведены составы

Составы твердого раствора и разрывы зон

\begin{tabular}{c|c|c|c|c|c}
\hline № & $\begin{array}{c}\text { Состав твердого } \\
\text { паствора }\end{array}$ & $\begin{array}{c}\Delta E_{v}, \\
\text { пэВ }\end{array}$ & $\begin{array}{c}\Delta E_{c}, \\
\text { мэВ }\end{array}$ & $\begin{array}{c}\text { Температура, } \\
\mathrm{K}\end{array}$ & Источник \\
\hline 1 & InAsSb $_{0.11} \mathrm{P}_{0.23}$ & $50^{*}$ & 135 & 300 & {$[9]$} \\
2 & $\operatorname{InAsSbP}_{0.18}$ & -30 & 119 & 300 & {$[10]$} \\
3 & InAsSb $_{0.04} \mathrm{P}_{0.09}$ & -58 & 134 & 77 & {$[32]$}
\end{tabular}

Примечание. * Приведен модуль значения величины разрыва зон. ** Для примера приведено лишь одно из множества значений, опубликованных в [32] для широкого диапазона составов твердого раствора InAsSbP. 


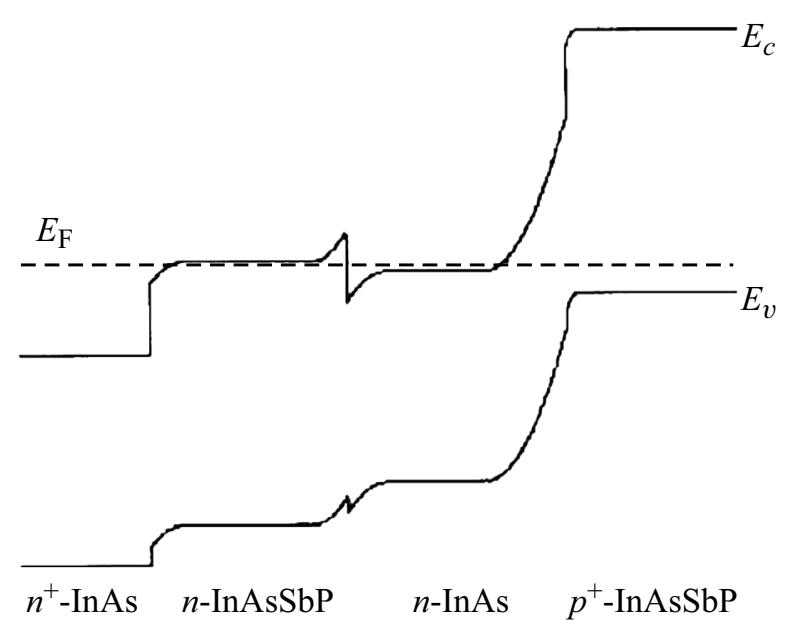

Pис. 1. Зонная диаграмма для ДГС InAsSbP/InAs, выращенной на сильнолегированной подложке $n^{+}$-InAs [10].

твердого раствора InAsSbP, а также расчетные значения разрывов зоны проводимости $\Delta E_{c}$ и валентной зоны $\Delta E_{v}$, опубликованные разными авторами $[9,10,32]$. Зонная диаграмма одной из исследованных ДГС InAsSbP/InAs приведена на рис. 1.

Наличие разрывов зон может иметь следствием возникновение потенциальных ям по обе стороны от границы раздела (ГР) InAsSbP/InAs; это обстоятельство учитывалось рядом авторов при интерпретации экспериментальных данных, главным образом особенностей спектров электролюминесценции (ЭЛ) ГС с „объемными“ слоями InAs толщиной в несколько мкм при комнатной температуре и при $77 \mathrm{~K}$. Так, например, в [24] смещение спектра ЭЛ светодиодной структуры в коротковолновую сторону при увеличении тока инжекции (в области малых токов) связывали с подъемом уровня Ферми в потенциальной яме на ГР InAs/InAsSbP. Увеличение энергии излучаемого кванта при подъеме уровня Ферми при температуре $T=77 \mathrm{~K}$ наблюдали также в ОГС $n^{+}$-InAs/n-InAs/ $p$-InAsSbP [25] и ранее в ДГС $n^{+}-\mathrm{InAs} / n-\mathrm{InAsSbP} / n-\mathrm{InAs} / p$-InAsSbP [33]. Из данных, приведенных в [24], следует, в частности, что при комнатной температуре вероятность рекомбинации на ГР превышает таковую в объеме структуры. Аналогичный вывод содержится и в работе [11], где утверждается, что при внешнем смещении за счет инжекции носителей заряда происходит заполнение самосогласованных потенциальных ям на ГР в изотипных ОГС $p$-InAs $\mathrm{As}_{0.66} \mathrm{Sb}_{0.11} \mathrm{P}_{0.23} / p$-InAs. При этом эффективность перекрытия волновых функций пространственно разделенных электронов и дырок вблизи гетерограницы II типа сушественно повышается за счет поджимания носителей заряда внешним электрическим полем и дальнейшей их аккумуляции на ГР. Это в свою очередь, согласно утверждению авторов [11], ведет к повышению вероятности излучательных рекомбинационных процес- сов, обусловленных туннелированием носителей заряда под потенциальными барьерами на ГР навстречу друг другу. Утверждается также, что для непрямых (интерфейсных) переходов характерна бо́льшая эффективность рекомбинации, чем для прямых межзонных, именно в силу своей „квантовой особенности“. Более того, вероятность непрямых (интерфейсных) излучательных рекомбинационных переходов на гетерогранице II типа $p$-InAsSbP/p-InAs была существенно больше даже при сохранении прямых межзонных (объемных) переходов в арсениде индия.

К сожалению, в работе [11] отсутствуют количественные оценки эффективности рекомбинации на интерфейсе, что не позволяет в полной мере оценить возможность создания мощных СД на основе изотипных ГС $p$-InAsSbP/p-InAs в частности из-за того, что при больших уровнях инжекции существенным образом увеличивается концентрация носителей заряда и соответственно можно ожидать увеличения скорости безызлучательной оже-рекомбинации в узких потенциальных ямах (см., например, соответствующую дискуссию об „интерфейсных“ СД на основе InAsSbP/InAs и СД с непрямыми излучательными переходами в [8]). До настоящего времени наиболее эффективными по-прежнему остаются СД с излучательными переходами в объеме InAs, а не на ГР.

В работе [26] было обращено внимание на совпадение энергии излучаемого кванта $h v$ и величины спин-орбитального отщепления $\Delta_{S O}$ в ДГС $n^{+}-\mathrm{InAs} / n-\mathrm{InAsSbP} /$ $n$-InAs/ $p$-InAsSbP при температуре $T=75 \mathrm{~K}$, при которой стимулированное излучение гасилось. Отсутствие стимулированного излучения при температурах $\sim 75 \mathrm{~K}$ объяснялось тем, что по мере увеличения температуры и уменьшения $E_{g}$ в активной области „резонансно включался“ оже-процесс CHHS, т.е. процесс, при котором энергия рекомбинирующей электронно-дырочной пары передается дырке с переходом последней в спин-орбитально отщепленную зону. По мнению авторов, при температурах > $77 \mathrm{~K}$ указанный оже-процесс „выключался“, однако стимулированная рекомбинация не наблюдалась из-за влияния других оже-процессов, подавлявших усиление.

В работе [12] высказывается не совпадающая с [26] точка зрения относительно основной причины уменьшения квантового выхода в ДГС $p$-InAsSbP $/ n$-InAs в интервале температур 85-120 K, а именно утверждается, что безызлучательный CHHS-процесс становится все более вероятным при повышении температуры. Значения коэффициента оже-рекомбинации $C$, представленные на рис. 2, были получены на основе расчетов скорости безызлучательной рекомбинации и концентрации носителей заряда. При этом величина внутреннего квантового выхода на пороге генерации для указанного выше интервала температур уменьшалась от 10.1 (плотность тока $\left.j=102 \mathrm{~A} / \mathrm{cm}^{2}, 85 \mathrm{~K}\right)$ до $7 \%(120 \mathrm{~K})$.

Экспоненциальный спад мощности ЭЛ $(P)$ при температурах $>300 \mathrm{~K}$, связанный с возрастанием скорости 


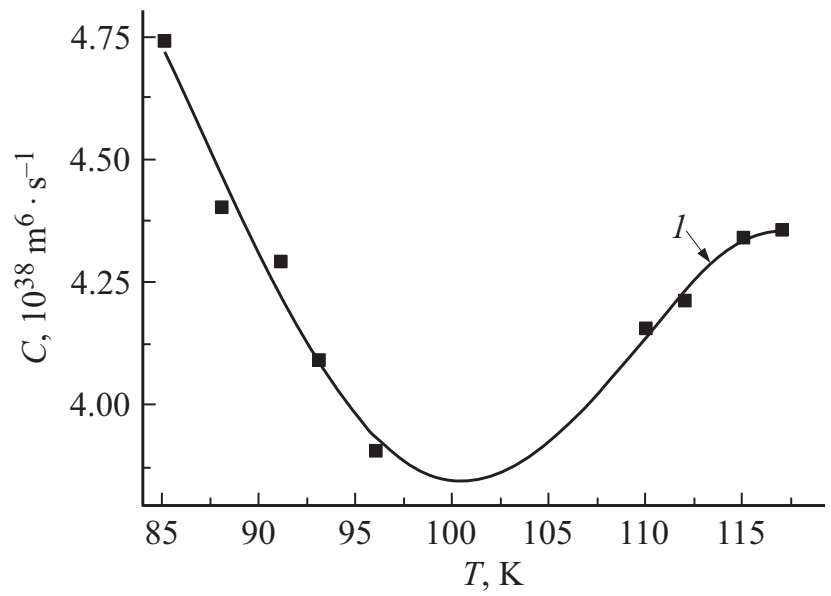

Рис. 2. Температурная зависимость коэффициента ожерекомбинации $C$, полученная путем сопоставления скоростей безызлучательной рекомбинации и концентрации $n$ (точки). 1 - аппроксимация $C(T)$ полиномом 3-го порядка [12].

оже-процессов $(P \propto \exp (2270 / T))$, был показан также в работе [27]. В работе [25] уменьшение величины сигнала ЭЛ при увеличении температуры от 77 до $300 \mathrm{~K}$, или, иными словами, коэффициент гашения люминесценции $\xi_{300 \mathrm{~K}}^{77 \mathrm{~K}}$, составил 14 . С учетом данных по коэффициенту поглощения $\alpha$, приведенных в [31] для $n^{+}-\operatorname{InAs}$ $\left(\alpha(85 \mathrm{~K}, 3\right.$ мкм $)=3 \mathrm{~cm}^{-1}, \alpha(300 \mathrm{~K}, 3.47$ мкм $)=14 \mathrm{~cm}^{-1}$, $\left.n^{+}=1.8 \cdot 10^{18} \mathrm{~cm}^{-3}\right)$, ожидаемое уменьшение пропускания подложки с характерной толщиной 200 мкм на длине волны максимума ЭЛ составляет $\sim 20 \%$. Поэтому можно полагать, что указанное гашение интенсивности ЭЛ в малой степени связано с изменением коэффициента вывода излучения, а в основном отражает изменение фундаментальных свойств арсенида индия, таких как внутренний квантовый выход $\eta_{\text {int. }}$ Полученные в $[25,26]$ результаты в целом соответствуют опубликованным ранее расчетным и экспериментальным данным о коэффициенте температурного гашения для спонтанного излучения (см., например, [5], где $\xi_{300 \mathrm{~K}}^{77 \mathrm{~K}}=30$ ) и о резком возрастании порогового тока в диодных лазерах на основе двойных гетероструктур InAsSbP/InAs начиная с температур $\sim 70 \mathrm{~K}$ из-за CHHS-процесса [34].

В работе [24] для импульсного режима питания СД была получена ватт-амперная $(L-I)$ характеристика, близкая к линейной зависимости вплоть до высоких значений плотностей тока $\left(j=4 \mathrm{kA} / \mathrm{cm}^{2}\right.$, ток $\left.I=10 \mathrm{~A}\right)$. Это является, безусловно, значительным техническим достижением, так как указывает, по-видимому, как на несущественность безызлучательной рекомбинации, так и на отсутствие уменьшения коэффициента вывода излучения из-за возможной локализации прохождения тока под непрозрачным точечным контактом при больших токах. Большинство же экспериментальных $[13,14]$ и расчетных [35] $L-I$-характеристик СД на основе InAs в области больших токов сублинейны, в том числе при охлаждении до температуры жидкого азота [23].
Так, например, согласно расчетам, проведенным в [35], при возрастании тока от $3\left(j=1 \mathrm{~A} / \mathrm{cm}^{2}\right)$ до $200 \mathrm{MA}$ $\left(j=70 \mathrm{~A} / \mathrm{cm}^{2}\right)$ ожидаемая внутренняя квантовая эффективность при $300 \mathrm{~K}$ в СД на основе ОГС InAsSbP/InAs диаметром 600 мкм с катодом диаметром 100 мкм уменьшается с 12 до 5\% (см. рис. 3), и поэтому исследователи по-прежнему видят основную задачу при создании СД в поиске способов подавления оже-рекомбинации [25].

В работе [24] приводятся значительно бо́льшие, чем в [35], значения внутреннего квантового выхода ЭЛ для плоского кристалла размером $500 \times 500$ мкм, для непрерывного $\left(\eta_{\text {int }}(300 \mathrm{~K})=19.5 \%, \quad I=20 \mathrm{MA}\right.$ $\left.\left(8 \mathrm{~A} / \mathrm{cm}^{2}\right)\right)$ и импульсного $\left(\eta_{\text {int }}(300 \mathrm{~K})=22.3 \%\right.$, $\left.I=290 \mathrm{MA}\left(116 \mathrm{~A} / \mathrm{cm}^{2}\right)\right)$ режимов работы СД с учетом коэффициента, учитывающего (оптические) потери на границе полупроводник/воздуха и равного $1 /\left[\bar{n}(\bar{n}+1)^{2}\right]$, где $\bar{n}=3.5-$ коэффициент преломления InAs. Полученные значения $\eta_{\mathrm{int}}(300 \mathrm{~K})$, хотя и не являются рекордными среди опубликованных ранее, но все же требуют критического осмысления, поскольку их трудно согласовать с оценками верхнего предела для этого
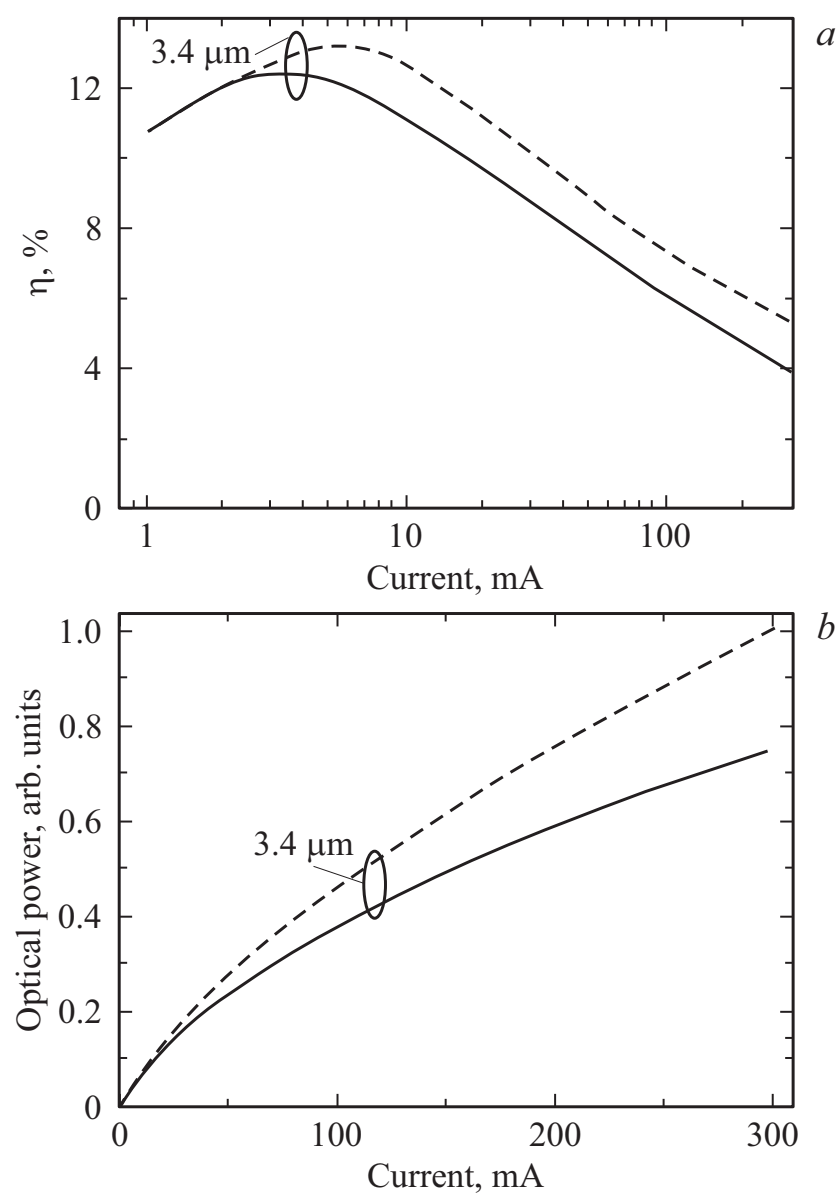

Рис. 3. Внутренняя квантовая эффективность $(a)$ и оптическая мощность светодиода $(b)$ на основе ОГC InAsSbP/InAs $(\lambda=3.4$ мкм, $300 \mathrm{~K})$. Сплошные кривые - расчет с учетом эффекта локализации, штриховые кривые - без учета локализации [35]. 
параметра с учетом уже упомянутых выше температурных зависимостей интенсивности ЭЛ (коэффициента гашения ЭЛ $\left.\xi_{300 \mathrm{~K}}^{77 \mathrm{~K}}\right): \eta_{\text {int }}(300 \mathrm{~K}) \leq \eta_{\text {int }}(77 \mathrm{~K}) / \zeta_{300 \mathrm{~K}}^{77 \mathrm{~K}}$, где $\eta_{\text {int }}^{(77 \mathrm{~K})} \leq 1, \quad$ a $\quad \xi_{300 \mathrm{~K}}^{77 \mathrm{~K}}=14-30 . \quad \mathrm{C}$ другой стороны, данные о температурной зависимости интенсивности ЭЛ в работе [24] в целом не противоречат опубликованным значениям коэффициента температурного гашения ЭЛ. Так, например, переход от импульсного к непрерывному режиму работы приводил, согласно утверждениям авторов, к нагреву активной области СД на $30^{\circ} \mathrm{C}$ и уменьшению мощности излучения в 5.7 раза при токе 1 А соответственно с 0.8 мВт до 140 мкВт.

По-видимому, завышенное, по нашему мнению, значение $\eta_{\text {int }}$ в работе [24] может быть связано с занижением коэффициента вывода излучения, в том числе из-за игнорирования отражения излучения от наклонных стенок мезы и от сплошного („нижнего“) контакта на основе $\mathrm{Cr}-\mathrm{Au}-\mathrm{Ni}-\mathrm{Au}$ на поверхности $p$-InAsSbP. Контакт такого состава по данным ряда работ (см. например, [15]) является отражающим. Наличие отражающего контакта вблизи от области рекомбинации в соответствии с [36] увеличивает коэффициент вывода излучения от 2 до 4 раз. Помимо этого, края полупроводникового кристалла, равно как и его углы, нередко являются дополнительными каналами для выхода излучения в окружающее чип пространство [15].

В области малых токов $\left(<1 \mathrm{~A} / \mathrm{cm}^{2}\right) L-I$-характеристики большинства СД имеют сверхлинейный вид, обусловленный влиянием рекомбинации Шокли-Рида (см., например, данные для диода площадью $1.6 \cdot 10^{-3} \mathrm{~cm}^{2}$ на рис. 3), что создает основу для ожиданий крайне низкой квантовой эффективности при сверхмалых токах накачки. Это справедливо лишь отчасти, поскольку в некоторых диодах влияния рекомбинации Шокли-Рида не наблюдалось вплоть до токов $0.1 \mathrm{~A} / \mathrm{cm}^{2}$ [14]. Более того, в области сверхмалых токов $(I \sim 100$ нА $)$ в инфракрасных (ИК) СД возможна реализация режима работы „теплового насоса“, при котором в результате термоэлектрического возбуждения при взаимодействии фононного и фотонного полей выделяющаяся в виде потока фотонов энергия превышает электрическую энергию, подаваемую в СД [37,38]. Такие СД обладают способностью забирать часть тепловой энергии от кристаллической решетки и трансформировать ее в энергию фотонов. Эффективность СД при этом может достигать значений, существенно бо́льших единицы, в том числе и при комнатной температуре в случае СД на основе ОГС $n^{+}-\mathrm{InAs} / n$-InAs/ $p$-InAsSbP [16]. На сегодняшний день „супервысокий“ кпд имеет место только в области малых токов (доли мкА), что пока ограничивает возможности для широкого практического применения таких „тепловых насосов“.

В обозначенный выше период не оставался без внимания и вопрос определения температурного коэффициента изменения длины волны излучения, измерение которого позволило авторам [27] получить выраже- ние для изменения ширины запрещенной зоны InAs c температурой, за пределами справедливости известной формулы из работы Fang et al. [1990] для диапазона $T<300 \mathrm{~K}$ (см. [39]): $E_{g}=0.4516-\left(3.2892 \cdot 10^{-4}\right) T$ для диапазона $T>300 \mathrm{~K}$, где $E_{g}$ в эВ.

\section{3. Вольт-амперные характеристики}

Опубликованные вольт-амперные характеристики $(\mathrm{BAX})$ для номинально близких ГС сильно разнятся что можно связать как с различиями в геометрических характеристиках конструкций СД, так и с различиями, возникающими из-за особенностей способов получения самих ГС. В работах [24,27] сообщается о туннельном механизме тока в ГС $p$-InAsSbP/n-InAs при больших токах и смешанном диффузионно-генерационном механизме тока в области малых токов при $300 \mathrm{~K}$. Туннельный механизм отмечался также и в работе [40], где $\mathrm{BAX}$ в обратной ветви имела гистерезис, связанный с джоулевым разогревом. При комнатной температуре в диодах с плавным $p$-n-переходом и широкими омическими контактами преобладает, как правило, диффузионный механизм токопрохождения [14].

Следует отметить, что вид ВАХ, описываемый обычно с помощью модифицированной формулы Шокли $I=I_{0}[\exp (\mathrm{eV} / \beta k T)-1]$, и соответственно значение фактора идеальности $\beta$, на основании которого производится отнесение токопрохождения к тому или иному типу, часто подвержен влиянию сопротивления контактного слоя и контактов, а также „геометрических“ факторов, под которыми понимаются вид, размер и расположение омических контактов. В этой связи повышенное значение фактора идеальности прямой ветви $\mathrm{BAX} \beta$ может быть обусловлено в том числе и упоминавшимся выше сгущением линий тока (или локализацией токопрохождения, английский термин current crowding), например, в СД на основе InGaN/GaN [41]. Применительно к плоским СД с точечным контактом на световыводящей поверхности на основе ОГС и ДГС $p$-InAsSbP/n-InAs в рамках простой феноменологической модели с учетом пространственного распределения излучения в ближнем поле $[10,17]$ (см. рис. 4) было определено, что локализация тока под точечным анодом приводит к завышенным значениям фактора идеальности прямой ветви ВАХ (при $300 \mathrm{~K} \beta=1.8$ и 1.56 для ДГС и ОГС соответственно) по сравнению с таковыми для диода с широкими анодом и катодом (при $300 \mathrm{~K} \beta=1.32$ и 1.07 для ДГС и ОГС соответственно). Указанные выше особенности/искажения BAX можно получить и при численном моделировании, т.е. без привлечения данных о пространственном распределении излучения, например, с использованием расчета, включающего вычисление латерального сопротивления проводников переменного сечения [18].

Следует отметить, что дополнительные барьеры также могут существенно влиять на параметры ВАХ в СД из InAs. Так, например, в $[10,17]$ наблюдалось увеличение 


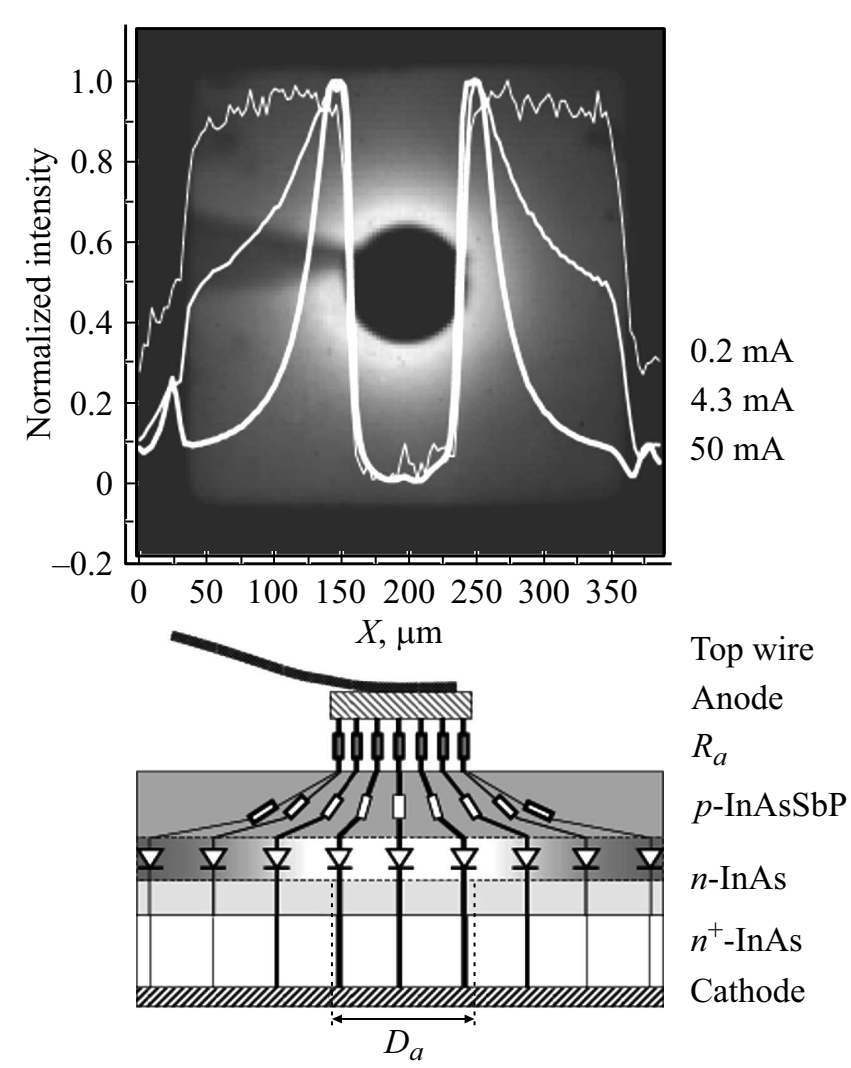

Рис. 4. $a$ - двумерное распределение интенсивности ЭЛ по поверхности и распределение интенсивности ЭЛ вдоль центрального сечения СД при токах $0.2,4.3$ и 50 мА, темному фону соответствует низкая, а светлому - высокая интенсивность излучения. $b-$ эквивалентная схема (в сечении) и состав слоев по данным [17]. Публикуется с разрешения SPIE.

динамического сопротивления в нуле смещения $R_{0}$ в ДГС по сравнению с ОГС из-за дополнительного скачка потенциала на изотипной ГР $n$-InAsSbP/n-InAs.

\section{4. Коэффициент вывода излучения}

Рассмотренная выше локализация тока под непрозрачным контактом является наряду с оже-рекомбинацией существенным фактором, ответственным за уменьшение внешней квантовой эффективности при больших токах в СД с точечным контактом. Степень этой ответственности может быть оценена с помощью фактора использования оптической мощности (ФИОМ, Ф), учитывающего затеняющее действие непрозрачного контакта для излучения, сформированного непосредственно под ним $[10,17,18]$ :

$\Phi=\left(\iint_{x} L(x, y) d x d y\right) /\left(S_{a} L_{\max }+\iint_{x} L(x, y) d x d y\right)$,

где $L(x, y)$ - интенсивность излучения в точке с координатами $x, y$ на поверхности контактного слоя $p$-InAsSbP, регистрируемая в ближнем поле, например, с помощью ИК камеры, $S_{a}$ - площадь анода, $L_{\max }-$ интенсивность излучения в непосредственной близости от анода.

На рис. 5 приведена зависимость ФИОМ от общего тока через СД на основе ОГС $p$-InAsSbP/n-InAs c круглым анодом диаметром 117 мкм, расположенным в центре квадратной мезы со стороной 385 мкм, полученная из данных о двумерном распределении интенсивности излучения с длиной волны $\sim 2.9$ мкм в ближнем поле [10]. Зависимость на рис. 5 можно понимать также и как зависимость внешнего квантового выхода в относительных единицах, поскольку нормированная на ФИОМ выходная мощность СД при токе, меньшем 20 мА, линейно зависела от него. Полученное изменение (по сути изменение внешнего квантового выхода) на рис. 5 сопоставимо с данными работы [35], в которой учет локализации тока приводит к уменьшению расчетной выходной мощности СД (см. рис. 3,b). Из изложенного выше следует, что при конструировании средневолновых ИК СД, так же как и для их „коротковолновых собратьев“" [36], важно учитывать растекание тока, зависящее от соотношения сопротивлений $p-n$-перехода, подложки, эпитаксиальных слоев и контактов в ГС. Одной из конструкций СД, минимизирующей негативный эффект от стягивания линий тока, и одновременно обеспечивающей эффективный отвод тепла от области рекомбинации носителей заряда, является флип-чип СД с сильно легированной подложкой $n$-типа проводимости и широким металлическим анодом $[2,6,8,13-16,19,21,26,27,33,42-46]$.

В настоящее время самым эффективным способом повышения коэффициента вывода излучения по-прежнему остается иммерсия чипа СД, т.е. создание оптического контакта полупроводниковой световыводящей поверхности с линзой с помощью оптически плотного материала. В качестве такого материала обычно рассматривается

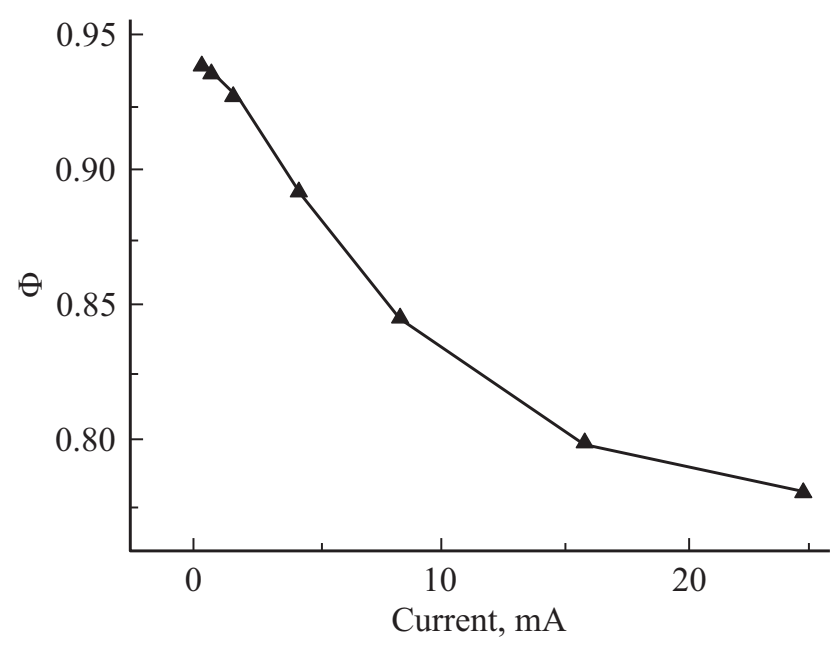

Рис. 5. Зависимость фактора использования оптической мощности от общего тока через СД на основе ОГС $p$-InAsSbP/n-InAs [10]. 


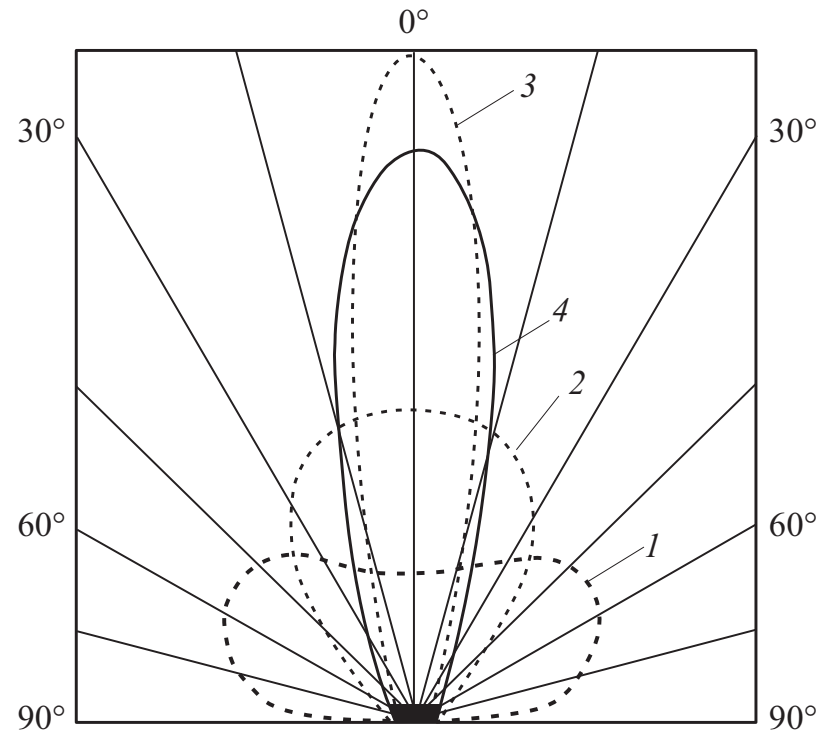

Рис. 6. Диаграмма направленности полупроводниковых источников ИК излучения. 1 - без оптического покрытия активных элементов, $2-$ с оптическим покрытием в виде полусферы, 3 - помещенных в параболический отражатель диаметром 80 мм, $4-$ с цилиндрической частью корпуса линзы из халькогенидного полупроводникового стекла [20].

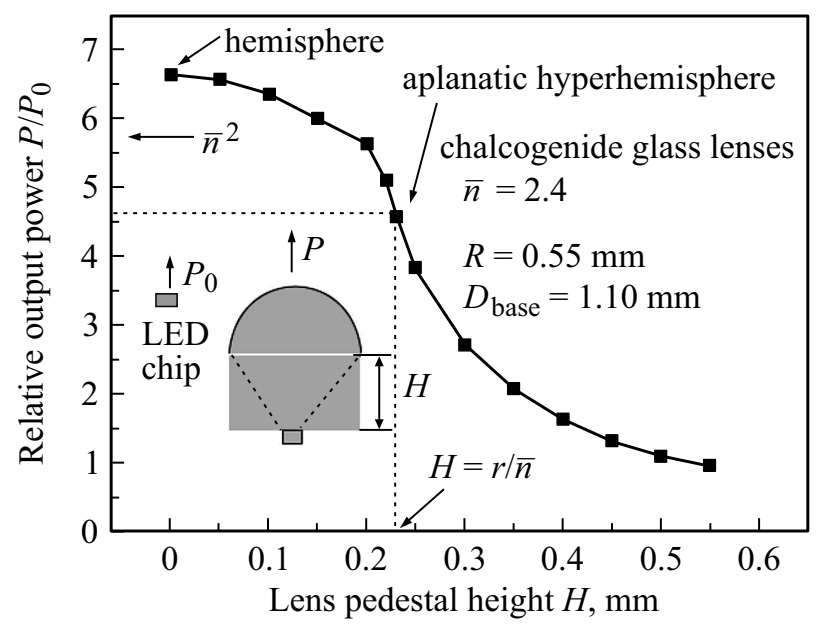

Рис. 7. Расчетная зависимость мощности излучения, вышедшего из светодиода $\left(P / P_{0}\right)$, состыкованного с линзой из халькогенидного стекла с показателем преломления $\bar{n}=2.4$, имеющей диаметр основания $D_{\text {base }}$, равный 1.1 мм и радиус кривизны $R=0.55$ мм, от высоты ее цилиндрической части $H$. Показатель преломления светодиода $\bar{n}_{\mathrm{LED}}=3.5$. На вставке схема, поясняющая условия расчета [21].

халькогенидное стекло с низкой температурой размягчения и высоким показателем преломления, $\bar{n}=2.3-2.4$, используемое как для стыковки с линзами из $\mathrm{Si}$, сапфира или $\mathrm{CdSb}[8,19]$, так и для создания собственно самой иммерсионной линзы $[8,19-21,47]$. Для кремниевых линз в форме гиперполусферы можно получить увеличенное изображение светоизлучающей области [19]; для линзы же из халькогенидного стекла получить такое изображение затруднительно, поскольку ее выпуклая поверхность создается за счет поверхностного натяжения расплавленного стекла и поэтому форма линзы трудно контролируема. После затвердевания стекла и формирования линзы диаграмма направленности СД заметно сужается, а интенсивность излучения возрастает благодаря частичному подавлению полного внутреннего отражения на ГР полупроводник/среда. Один из примеров диаграмм направленности излучения СД с иммерсионной линзой из халькогенидного стекла приведен на рис. 6 [20]. Следует отметить, что вытянутость диаграммы направленности зависит в том числе и от соотношения размеров активной области СД и халькогенидной линзы [48].

Влияние формы иммерсионной линзы с $\bar{n}=2.4$ на коэффициент вывода излучения можно показать расчетами, проведенными для линзы, имеющей сферическую поверхность радиусом $r=0.55$ мкм и с цилиндрическим основанием диаметром 1.1 мм, высотой (пьедесталом) $H$ (рис. 7) [21].

Из данных рис. 7 следует, что в СД с полусферической линзой $(H \rightarrow 0)$ благодаря ее высокому показателю преломления ожидается получение мощности излучения $P$, в $\sim 6.5$ раза превосходящей мощность для плоского СД без специальных покрытий, $P_{0}$. Для линзы в виде гиперполусферы Вейерштрасса $(H=r / \bar{n})$ фактор увеличения мощности составляет $\sim 4.6$, что с учетом направленности излучения делает СД с подобными линзами привлекательными для практического использования. Вдвое большее увеличение мощности (до 10 раз) было получено для СД, снабженного линзой с несколько бо́льшими, чем в [21], размерами, а именно: $r=2.6 \mathrm{MM}, H=1.15 \mathrm{Mм}[47]$.

\section{5. Вопросы практического применения светодиодов на основе InAs}

За прошедшие 10 лет сфера применения СД на основе InAs заметно расширилась, в том числе благодаря отработке технологии получения СД с иммерсионными линзами. Так, например, благодаря использованию сферического отражателя и СД с микроиммерсионными линзами, т.е. СД с радиусами кривизны линзы $r \approx 500$ мкм, удалось осуществить эффективную оптическую стыковку СД с миниатюрной дифференциальной оптико-акустической ячейкой размерами $14 \times 8 \times 4$ мм, в которой чувствительный элемент в виде двойной (дифференциальной) газовой камеры, разделенной кантилевером и наполненной метаном, имел диаметр входного окна всего лишь 2.4 мм [42-44]. Наполнение дифференциальной ячейки метаном обеспечивало селективность чувствительности к метану; сама же измеряемая смесь находилась на открытом оптическом пути между СД и фотоакустической ячейкой. На рис. 8 представлены расчеты мощности излучения $P_{m}$, собираемого сферическим зеркалом с радиусом отражающей поверхности 


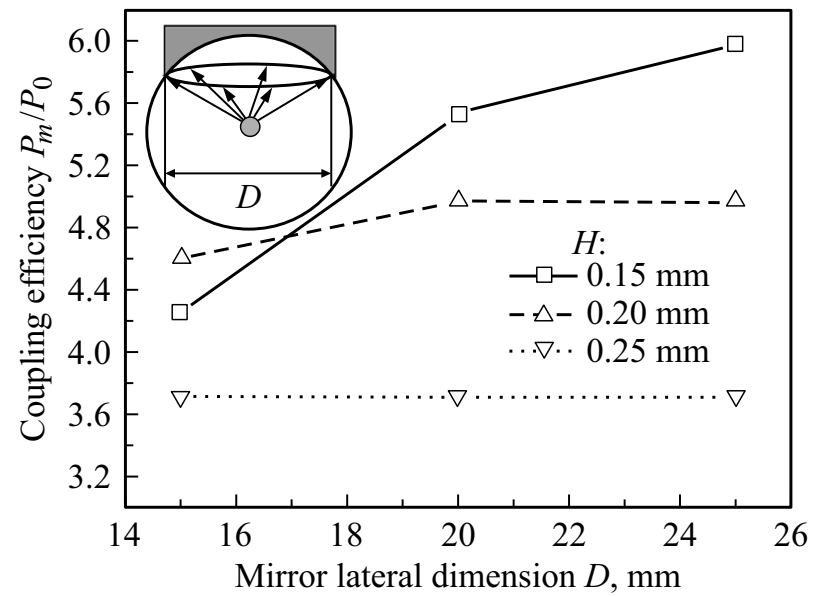

Рис. 8. Зависимость мощности, собираемой сферическим зеркалом, $P_{m} / P_{0}$, от его поперечного диаметра. Высота цилиндрической части линзы $H: 0.15,020$ и 0.25 мм. $P_{0}-$ полная мощность излучения исходного плоского (без линзы) СД [36].

15 мм, в зависимости от поперечного диаметра зеркала $(D)$ для разных значений высоты пьедестала микроиммерсионной линзы $(H)[19,21]$. Как видно из рис. 8 , для СД с наиболее высокой линзой $(H=0.25 \mathrm{мм})$ имеет место неизменность эффективности сбора излучения при варьировании светосилы из-за высокой направленности излучения СД. Вместе с тем значение мощности собираемого зеркалом излучения $P_{m}$ невелико из-за малого угла сбора излучения внутри полупроводникового кристалла. Значение $P_{m}$ можно повысить при уменьшении $H$ или увеличении угла сбора излучения внутри кристалла, при этом, естественно, для эффективного использования оптической мощности необходимо использование светосильного зеркала.

Описанный выше сенсор, в котором в измерительном канале СД с микроиммерсионной линзой $(\lambda=3.4$ мкм, 120 мкВт при $I=100$ мА в непрерывном режиме $(\mathrm{CW}))$ был оптически состыкован с измерительной газовой кюветой с помощью сферического зеркала диаметром 12 мм и с фокусным расстоянием 6 мм, имел порог обнаружения $300 \mathrm{ppm}$ при времени измерения $1 \mathrm{c}$ или 30 pрm при времени усреднения 100 с [42].

Неселективный к углеводородным газам фотоакустичесий сенсор с несколько большей, чем в [42], оптической длиной взаимодействия излучения СД и метана, описан в [45]. При использовании цилиндрической оптической кюветы длиной $L=42$ мм и диаметром $D=5$ мм, оптически состыкованной с иммерсионным светодиодом с кремниевой линзой диаметром 3.5 мм $(\lambda=3.4$ мкм, 150 мкВт при $I=200$ мА), порог обнаружения метана при времени усреднения 1 с составил 26 ppm.

В работе [49] в качестве источника зондирующего излучения в оптико-акустическом газоанализаторе был использован иммерсионный СД LED34Sr с кремниевой линзой диаметром $3.5 \mathrm{Mм}(\lambda=3.4$ мкм, 200 мкВт), а в качестве детектора импульсного изменения давления биогаза (т.е. смеси метана и двуокиси углерода) был использован пьезоэлектрический датчик резонансного типа на основе кварца (частота $f_{r}=32.768$ кГц). При длине оптического пути $L_{\text {methane }}=4$ см и времени усреднения сигнала 10 с погрешность измерения концентрации метана была $<1 \%$ для диапазона 40-60 об\%.

В первых двух вышеприведенных случаях регистрация амплитуды и фазы оптико-акустической волны осуществлялась с помощью измерений местоположения „языка“ кремниевого кантилевера с помощью интерферометра. Такая система считывания, впрочем, как и измерение с помощью пьезоэлектрического датчика в [49], подвержена влиянию вибрационных шумов и поэтому не всегда может быть успешно применена на практике. Более устойчивым к вибрациям способом измерений является регистрация относительного изменения пропускания среды, тем более, что для диапазона длин волн 3-4 мкм имеется широкая номенклатура промышленно выпускаемых фотоприемников, в том числе и из InAs.

В работе [46] проведены расчеты инструментальной функции и передаточной характеристики газоанализатора этилена на основе иммерсионных СД и фотодиода (ФД) с активным слоем из InAs c длиной оптического пути $4.5 \mathrm{~cm}$. Для режима в 10 отсчетов в $1 \mathrm{c}$ экспериментально определенное значение отношения сигнал/шум составляло $S N R=3 \cdot 10^{3}$ (время усреднения $0.1 \mathrm{c}$ ) для диапазона измерений $0-50$ об\%. Несколько меньшее отношение сигнал/шум (SNR > 100) было зафиксировано при использовании в качестве приемника излучения фотосопротивления $\mathrm{PbSe}$, иммерсионного СД $(\lambda=3.32$ мкм, 150 мкВт, $I=300 \mathrm{мA})$ и диффузионно рассеивающей (интегрирующей) сферы в [50]. Минимальный порог обнаружения метана такого сенсора составил 200-250 ppm (время усреднения сигнала в [50] не указано). Близкое к этому значение порога обнаружения было получено при времени усреднения $\sim 2$ с, использовании оптической кюветы размером $55 \times 26 \times 14$ мм и СД и ФД на основе ОГС $p$-InAsSbP/n-InAs [28]. Для диодного сенсора с оптической длиной 60 мм на основе трех СД с длинами волн 3.2, 3.4 и 3.7 мкм и ФД из InAs погрешность измерений метана в диапазоне $0-100$ об\% составила $0.5 \%$ [29] (в работе [29] время усреднения сигнала не указано).

В работах $[51,52]$ был описан газоанализатор на основе оптически согласованных иммерсионных СД и ФД с максимумом спектральной кривой при 3.4 мкм (см. рис. 9) для мониторинга концентрации углеводородов, испаряющихся с поверхности сырой нефти. ${ }^{1}$ При энергопотреблении 4Вт [51], длине оптического пути $<10$ см погрешность измерения концентраций $n$-гексана и мета-

\footnotetext{
${ }^{1}$ В статье [51] есть опечатка на с. 106: разработчик и производитель описываемых СД и фотодиода указан, по-видимому, неверно. По нашему мнению, производитель использованных в работе компонентов - ООО „ИоффеЛЕД“ (СПб), как это следует, например, из текста в публикации [А.О. Васильев. Автореф. канд. дис. СПб, 2012] и спецификации продукции, выпускаемой ООО „ИоффеЛЕД“.
} 


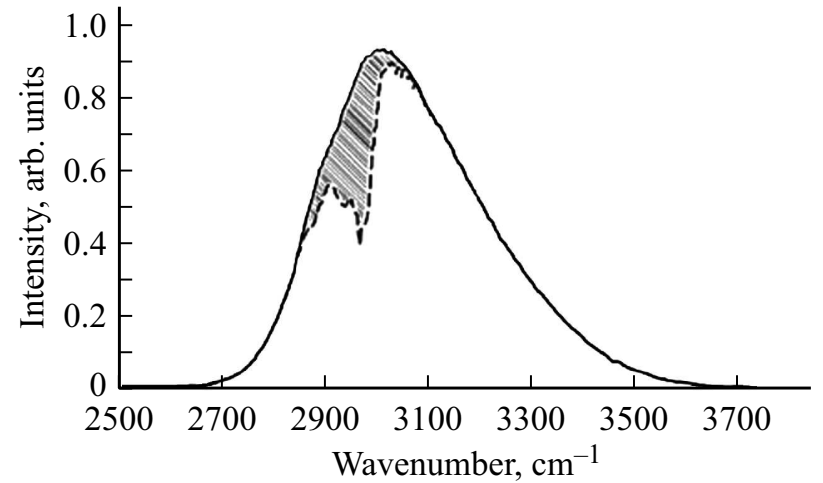

Рис. 9. Исходный спектр излучения СД при $300 \mathrm{~K}$ (сплошная линия) и спектр, получаемый после прохождения излучения через газовую смесь, содержащую углеводороды (штриховая линия) [52]). Публикуется с разрешения SPIE.

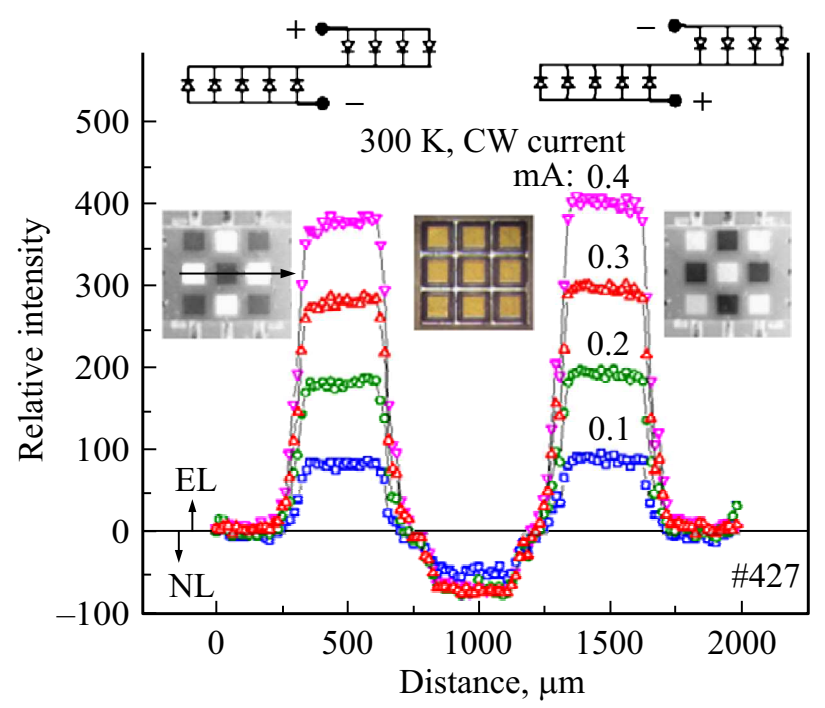

Рис. 10. Распределение интенсивности ОЛ (NL) и ЭЛ (EL) матрицы $3 \times 3$ вдоль ее центрального сечения при одновременном подключении всех элементов к источнику питания по схеме, представленной в левом верхнем углу рисунка. На вставках - фотография матрицы со стороны слоя $p$-InAsSbP (в центре), ИК изображения при общем токе через матрицу 100 мкА при двух вариантах включения, показанных в верхней части рисунка [13].

на составила 2.15 и $1.2 \%$ соответственно [52]. При этом энергопотребление в аналогичных сенсорах на основе пары СД-ФД может быть снижено до 50 мкВт [30].

Помимо использования в аналитических приборах, СД также находят применение для тестирования/контроля многих параметров фотоприемников, например таких, как быстродействие и пространственная однородность фоточувствительности матричных ИК фотодетекторов [53]. В этой связи создание тестовых объектов в виде линеек и матриц СД в средневолновой ИК области спектра представляется актуальной задачей. В работах $[13,14]$ представлены результаты исследований ма- лоформатных диодных матриц $3 \times 3$ и $8 \times 8$ на основе ОГС $p$-InAsSbP $/ n$-InAs c индивидуальной адресацией элементов. На рис. 10 показано распределение интенсивности люминесцентного излучения при одновременном подключении всех элементов матрицы формата $3 \times 3$ к источнику питания. В данном эксперименте диодные элементы были объединены в две группы, состоящие из 4 и 5 элементов соответственно, как показано на вставках к рис. 10. На правой вставке приведено ИК изображение поверхности матрицы, полученное при постоянном токе $\sim(-25$ мкА $)$ в каждом из 4 недиагональных элементов, работающих в режиме отрицательной люминесценции (ОЛ), т.е. в режиме пониженной по сравнению с равновесным фоном излучательной способности (темные квадраты), и токе $\sim 20$ мкА в каждом из диагональных и центральном элементах, работающих в режиме ЭЛ (светлые квадраты, повышенная по сравнению с фоном яркость излучения). В другом эксперименте (см. левую вставку) 4 диагональных и центральный элементы матрицы работали в режиме ОЛ (ток через элемент $I_{\text {pixel }} \approx-20$ мкА), а 4 оставшихся в режиме ЭЛ $\left(I_{\text {pixel }} \approx 25\right.$ мкА $)$. Амплитуда общего тока в обоих случаях формирования ИК изображения типа „шахматной доски““ составляла 100 мкА. ${ }^{2}$

Из данных рис. 10 следует, что при токе через элемент 20 мкА интенсивности ОЛ и ЭЛ практически совпадают, а при больших токах имеет место слабая зависимость интенсивности ОЛ от тока - хорошо известная особенность приборов ОЛ, вызванная почти полной экстракцией носителей из активной области [54]. Можно отметить также однородность матрицы - различие в интенсивности ЭЛ ее крайних элементов (пикселей) не превышало 10\%. Зависимость интенсивности излучения одиночного элемента от тока представлена на рис. 11; при этом согласно градуировке ИК микроскопа плотность электролюминесцентного излучения при токе $1.6 \mathrm{MA}\left(17 \mathrm{~A} / \mathrm{cm}^{2}\right)$ соответствовала потоку излучения от эталона, нагретого до $73^{\circ} \mathrm{C}$ (для калибровки использовалась пластина просветленного арсенида индия, температура которой контролировалась термопарой). На этом же рисунке приведена вольт-амперная характеристика. Произведение динамического сопротивления в нуле смещения $\left(R_{0}\right)$ на площадь $p-n$-перехода $\left(A_{p-n}\right)$ составляло $\sim 1.3 \mathrm{OM} \cdot \mathrm{cm}^{2}$ при $293 \mathrm{~K}$. Его температурная зависимость линеаризовалась в координатах $\ln \left(R_{0}\right)-1 / T$, при этом энергия активации составляла $E_{a}=0.5$ эВ, что близко к величине запрещенной зоны InAs и свидетельствует в пользу доминирования диффузионного тока, по крайней мере при малых токах.

Довольно часто разработчики и производители средневолновых ИК СД предпочитают использовать достаточно толстые полупроводниковые слои, в которых

\footnotetext{
2 Термин „шахматная доска“ был использован в работе [В.К. Малютенко. Infr. Phys. Technol., 44, 11 (2003)] применительно к магнитоконцентрационным матричным источникам $16 \times 16$ на основе объемного антимонида индия. В нашем случае мы пока имеем дело, скорее всего, с ,доской“ для „крестиков-ноликов“.
} 


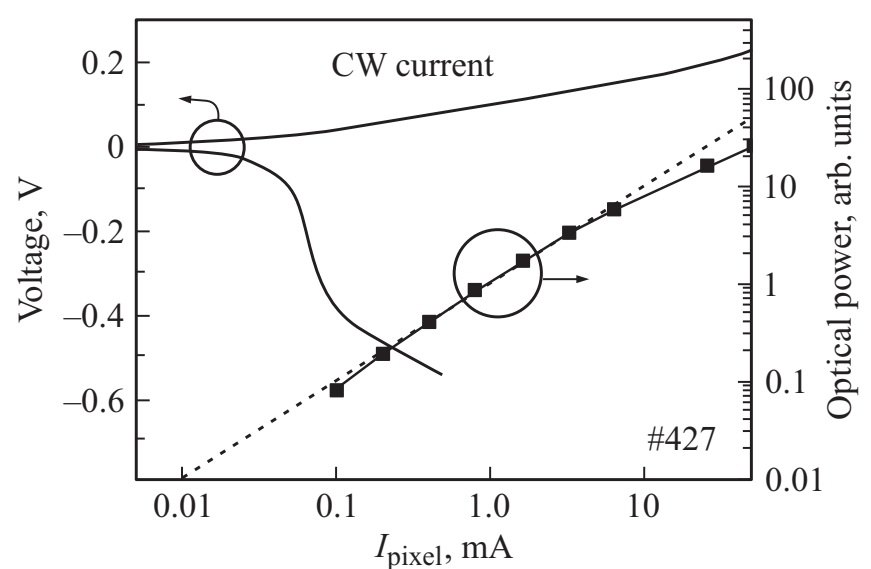

Рис. 11. Зависимость интенсивности ЭЛ от значения постоянного тока через элемент матрицы $3 \times 3$-InAsSbP/ $n$-InAs $/ n^{+}$-InAs, полученная из данных на рис. 10 , и вольт-амперная характеристика ее элемента [13].

инжектированные носители заряда „размазываются“ по всему объему активной области. В результате достигается относительно низкая концентрация инжектированных носителей и соответственно низкая скорость оже-рекомбинации. Разумеется, что при этом верхняя граница для толщины активной области выбирается исходя из возможности вывода излучения из этой области с учетом самопоглощения излучения. В результате оптимальная толщина активной области СД часто оказывается сопоставимой с оптимальной толщиной поглощающего слоя, необходимой для эффективной работы ФД. Другими словами, эффективный средневолновый ИК СД нередко оказывается одновременно и эффективным ФД. Действительно, ФД на основе ОГС $p$-InAsSbP $/ n$-InAs, схожий конструктивно со СД, имеет характеристики, определяемые ,правилом $07^{\text {“ }}$ (,rule $07^{\text {“ }}$ ) [22], т.е. соответствует предельным возможностям современной технологии. Это обстоятельство может быть учтено при проектировании различной оптоэлектронной аппаратуры включая газоанализаторы. Так, например, в [55] для повышения точности при фотометрических измерениях включая газовый анализ было предложено поочередно использовать один и тот же диод то в качестве приемника, то в качестве калибровочного источника ИК излучения.

\section{6. Заключение}

В прошедшие 10 лет арсенид индия по-прежнему был основным материалом для получения электролюминесцентного излучения вблизи основной полосы поглощения углеводородов $(\lambda=3.4$ мкм, $300 \mathrm{~K})$. При этом, как нетрудно заметить, доля работ, посвященных практическим аспектам применения СД, заметно выросла. На наш взгляд, это связано как с освоением методов выращивания светодиодных структур на под- ложках большой площади, так и с возросшим качеством омических контактов и сборок СД, что делает их практическое применение все более надежным и оправданным. Последнее стало возможным в том числе благодаря изучению пространственного растекания тока, влияния геометрии контактов на эффективность СД и переходе производителей к более продвинутым конструкциям СД, например к иммерсионным СД „перевернутого“ типа с отражающими контактами или „флип-чип“, в которых увеличение плотности тока, локализация тока сведены к минимуму и увеличен коэффициент вывода излучения.

Наименьшие значения порога обнаружения метана в газоанализаторах, использующих СД, на момент написания статьи были реализованы в оптико-акустических приборах, использующих микрофон кантилеверного типа (26 ppm при времени усреднения 1 c). В то же время проведение полноценного сравнения характеристик точности и погрешности сенсоров на основе оптопар затруднительно, поскольку большинство статей не содержит всей совокупности необходимых для анализа и сравнения данных.

В связи с экспериментальным наблюдением эффекта термоэлектрического возбуждения и кпд $>1$ в диодах из InAsSbP/InAs открывается возможность создания в будущем оптоэлектронных сенсоров с „ультранизким энергопотреблением“", что важно для некоторых специфических применений, например, в медицине (оксиметрия) [56,57]. Сенсоры на основе средневолновых ИК СД и ФД представляют интерес и при обычном (без термоэлектрического возбуждения) режиме работы, при котором кпд $\ll 1$; при этом терминологически их правильнее отнести к „низковольтному“ типу сенсоров [58], а не к сенсорам со „сверхнизким энергопотреблением“ (термин, используемый в [30]).

По-прежнему для СД из InAs остается немало „белых пятен“; так, например, нам удалось обнаружить лишь две работы, содержащие упоминание об измерении шумов в диодах из InAs $[59,60]$. Для других типов СД, например СД из $\mathrm{GaN}$, изучение шумов проводится достаточно активно в связи с возможностью более детального исследования рекомбинационных процессов и механизмов деградации их излучательных свойств. Можно выразить надежду, что работы аналогичной направленности применительно к СД из InAs появятся в ближайшем будущем, а сами СД станут еще более надежными.

Авторы выражают благодарность сотрудникам лаборатории инфракрасной отптоэлектроники ФТИ им. А.Ф. Иоффе РАН за полезные обсуждения.

Работа, выполненная в ООО „ИоффеЛЕД“, поддержана проектом ФЦП „Разработка фоточувствительных элементов большой размерности для спектральных областей $2.5-3.5,2.5-4.5,2.5-5.5$ мкм на основе диодных гетероструктур из InAs и твердых растворов InAsSbP,“ (код контракта 14.576.21.0104, ID: RFMEFI57618X0104). 


\section{Список литературы}

[1] J. Hodgkinson, R.P. Tatam. Meas. Sci. Technol., 24, 012004 (2013).

[2] Б.А. Матвеев. Фотоника, 6 (48), 80 (2014).

[3] X. Zhou, X. Meng, A.B. Krysa, J.R. Willmott, J.S. Ng, Ch.H. Tan. IEEE Sens. J., 15 (10), 5555 (2015).

[4] D. Zymelka, B. Matveev, S. Aleksandrov, G. Sotnikova, G. Gavrilov, M. Saadaoui. IOP J. Flexible Printed Electronics, 2, 045006 (2017). DOI: 10.1088/2058-8585/aa900a.

[5] М. Айдаралиев, Н.В. Зотова, С.А. Карандашев, Н.М. Стусь. ФТП, 23 (1), 592 (1989).

[6] B.A. Matveev, N.V. Zotova, N.D. Il'inskaya, S.A. Karandashev, M.A. Remenyi, N.M. Stus', A.P. Kovchavtsev, G.L. Kuryshev, V.G. Polovinkin. Mater. Res. Soc. Symp. Proc., 891, 9 (2006).

[7] I. Vurgaftman, J.R. Meyer, L.R. Ram-Mohan. J. Appl. Phys., 89 (11), 5815 (2001).

[8] Н.В. Зотова, Н.Д. Ильинская, С.А. Карандашев, Б.А. Матвеев, М.А. Ременный, Н.М. Стусь. ФТП, 42 (6), 641 (2008).

[9] М.М. Григорьев, Э.В. Иванов, К.Д. Моисеев. ФТП, 45 (10), 1386 (2011).

[10] Н.В. Зотова, С.А. Карандашев, Б.А. Матвеев, М.А. Ременный, А.Ю. Рыбальченко, Н.М. Стусь. ФТП, 45 (4), 554 (2011).

[11] М.М. Григорьев, П.А. Алексеев, Э.В. Иванов, К.Д. Моисеев. ФТП, 47 (1), 30 (2013).

[12] В.В. Кабанов, Е.В. Лебедок, А.Г. Рябцев, Г.И. Рябцев, М.А. Щемелев, В.В. Шерстнев, А.П. Астахова, Ю.П. Яковлев. ФТП, 43 (4), 522 (2009).

[13] Н.Д. Ильинская, С.А. Карандашев, Н.Г. Карпухина, А.А. Лавров, Б.А. Матвеев, М.А. Ременный, Н.М. Стусь, А.А. Усикова. Прикл. физика, № 6, 47 (2014).

[14] P.N. Brunkov, N.D. Il'inskaya, S.A. Karandashev, A.A. Lavrov, B.A. Matveev, M.A. Remennyi, N.M. Stus', A.A. Usikova. Infr. Phys. Technol., 78, 249 (2016). http://dx.doi.org/10.1016/j.infrared.2016.08.013

[15] А.Л. Закгейм, Н.Д. Ильинская, С.А. Карандашев, А.А. Лавров, Б.А. Матвеев, М.А. Ременный, Н.М. Стусь, А.А. Усикова, А.Е. Черняков. ФТП, 51 (2), 269 (2017).

[16] P. Santhanam, D. Huang, R.J. Ram, M.A. Remennyi, B.A. Matveev. Appl. Phys. Lett., 103 (19), 183513 (2013). DOI: $10.1063 / 1.4828566$.

[17] B.A. Matveev, A.V. Ankudinov, N.V. Zotova, S.A. Karandashev, T.V. L'vova, M.A. Remennyy, A.Yu. Rybal'chenko, N.M. Stus'. Proc. SPIE, 7597, 75970G (2010).

[18] С.А. Карандашев, Б.А. Матвеев, В.И. Ратушный, М.А. Ременный, А.Ю. Рыбальченко, Н.М. Стусь. ЖТФ, 84 (11), 52 (2014).

[19] Н.В. Зотова, С.А. Карандашев, Б.А. Матвеев, М.А. Ременный, Н.М. Стусь. Оптический журн., 79 (9), 60 (2012).

[20] В.Н. Кабаций. Технология и конструирование в электронной аппаратуре, № 4, 30 (2008).

[21] B. Matveev, M. Remennyy, S. Karandashev, K. Keränen, H. Saloniemi, J. Ollila, T. Kuusela, I. Kauppinen. Proc. IMCS 2012 - 14th Intern. Meeting on Chemical Sensors (Nürnberg/Nuremberg, Germany, 2012) p. 241. DOI: 10.5162/IMCS2012/2.5.5.

[22] Н.Д. Ильинская, С.А. Карандашев, А.А. Лавров, Б.А. Матвеев, М.А. Ременный, Н.М. Стусь, А.А. Усикова. Сб. тез. Росс. конф. и школы молодых ученых по актуальным проблемам полупроводниковой фотоэлектроники (с участием иностранных ученых) ФОТОНИКА 2017 (Новосибирск, 2017) с. 18. ISBN 978-5-4437-0673-3.
[23] Н.С. Аверкиев, А.П. Астахова, Е.А. Гребенщикова, Н.Д. Ильинская, К.В. Калинина, С.С. Кижаев, А.Ю. Кислякова, А.М. Монахов, В.В. Шерстнев, Ю.П. Яковлев. ФТП, $43(1), 124$ (2009).

[24] А.П. Астахова, А.С. Головин, Н.Д. Ильинская, К.В. Калинина, С.С. Кижаев, О.Ю. Серебренникова, Н.Д. Стоянов, Zs.J. Horvath, Ю.П. Яковлев. ФТП, 44 (2), 278 (2010).

[25] Н.К. Жумашев, К.Д. Мынбаев, Н.Л. Баженов, Н.Д. Стоянов, С.С. Кижаев, Т.И. Гурина, А.П. Астахова, А.В. Черняев, С.С. Молчанов, Х. Липсанен, Х.М. Салихов, В.Е. Бугров. Науч.-техн. вестн. инбормационных технологий, механики и оптики, 16 (1), 76 (2016).

[26] К.Д. Мынбаев, Н.Л. Баженов, А.А. Семакова, М.П. Михайлова, Н.Д. Стоянов, С.С. Кижаев, С.С. Молчанов, А.П. Астахова, А.В. Черняев, Н. Lipsanen, В.Е. Бугров. ФТП, 51 (2), 247 (2017).

[27] А.А. Петухов, Н.Д. Ильинская, С.С. Кижаев, Н.Д. Стоянов, Ю.П. Яковлев. ФТП, 45 (11), 1560 (2011).

[28] С.С. Кижаев, К.В. Калинина, А.А. Петухов, Т.И. Гурина, А.Н. Миронова, А.В. Черняев, Н.Д. Стоянов, Х.М. Салихов. Тр. 2-й Российско-Белорусской науч.-техн. конф. „Элементная база отечественной радиоэлектроники: импортозамещение и применение и им. О.В. Лосева (Н. Новгород, 2015) с. 163. ISBN 978-5-9903092-3-8.

[29] N.D. Stoaynov, K.M. Salikhov, K.V. Kalinina, B.E. Zhurtanov, S.S. Kizhaev. Proc. SPIE, 8257, 82571E (2012).

[30] N.D. Stoyanov, K.M. Salikhov, K.V. Kalinina, S.S. Kizhaev, A.V. Chernyaev. Proc. SPIE, 8982, 89821A (2014).

[31] О.С. Комков, Д.Д. Фирсов, Е.А. Ковалишина, А.С. Петров. Прикл. физика, № 4, 93 (2014).

[32] K. Shim. Jpn. J. Appl. Phys., 55, 011201 (2016).

[33] B. Matveev, N. Zotova, N. Il'inskaya, S. Karandashev, M. Remenyi, N. Stus'. Phys. Status Solidi C, 2 (2), 927 (2005).

[34] М. Айдаралиев, Г.Г. Зегря, Н.В. Зотова, С.А. Карандашев, Б.А. Матвеев, Н.М. Стусь, Г.Н. Талалакин. ФТП, 26 (2), 246 (1992).

[35] Я.Я. Кудрик, А.В. Зиновчук. Письма ЖТФ, $38(10), 14$ (2012).

[36] E.F. Schubert. Light-Emitting Diodes, 2nd edn (Cambridge University Press, Cambridge, UK, 2006).

[37] P. Santhanam, D.J. Gray, jr., R.J. Ram. Phys. Rev. Lett., 108, 097403 (2012).

[38] P. Santhanam, D. Huang, D.J. Gray, jr., R.J. Ram. Proc. SPIE, 8638, 863807 (2013). DOI: 10.1117/12.2005093.

[39] http://www.matprop.ru/InAs_bandstr

[40] S. Rathgeb, J.-P. Moeglin, A. Boffy, M. Pasquinelli, O. Palais. Appl. Phys. Lett., 89, 022106 (2006).

[41] V.K. Malyutenko, S.S. Bolgov, A.D. Podoltsev. Appl. Phys. Lett., 97 (25), 251110 (2010).

[42] K. Keränen, J. Ollila, H. Saloniemi, B. Matveev, J. Raittila, A. Helle, I. Kauppinen, T. Kuusela, L. Pierno, P. Karioja, M. Karppinen. Procedia Engin., 47, 1438 (2012).

[43] K. Keränen, K. Kautio, J. Ollila, M. Heikkinen, I. Kauppinen, T. Kuusela, B. Matveev, M.E. Mc Nie, R.M. Jenkins, P. Karioja. Proc. SPIE, 7607, 760714 (2010).

[44] P. Karioja, K. Keranen, K. Kautio, J. Ollila, M. Heikkinen, I. Kauppinen, T. Kuusela, B. Matveev, M.E. Mc Nie, R.M. Jenkins, J. Palve. Proc. SPIE, 7726, 77260H (2010).

[45] T. Kuusela, J. Peura, B.A. Matveev, M.A. Remennyy, N.M. Stus'. Vibrational Spectroscopy, 51 (2), 289 (2009).

[46] G.Yu. Sotnikova, S.E. Aleksandrov, G.A. Gavrilov. Proc. SPIE, 7356, 73561T (2009).

[47] V.A. Markov, A.V. Semencha, M.V. Kurushkin, D.V. Kurushkin, V.A. Klinkov, A.A. Petukhov. Infr. Phys. \& Technol., 78, 167 (2016). http://dx.doi.org/10.1016/j.infrared.2016.07.020 
[48] Н.П. Есина, Н.В. Зотова, И.И. Марков, Б.А. Матвеев, А.А. Рогачев, Н.М. Стусь, Г.Н. Талалакин. Журн. прикл. спектроскопии, 42 (4), 691 (1985).

[49] M. Köhring, S. Böttger, U. Willer, W. Schade. Sensors (Basel), 15 (5), 12092 (2015). DOI: 10.3390/s150512092

[50] В.Н. Кабаций. Технология и конструирование в электронной аппаратуре, № 3, 29 (2010).

[51] А.О. Васильев, П.В. Чартий, В.Г. Шеманин. Петербургский журн. электроники, № 1, 101 (2010).

[52] A.O. Vasilyev, V.G. Shemanin, P.V. Chartiy. Proc. SPIE, 8155, 81550T (2011).

[53] И.И. Ли, В.М. Базовкин, Н.А. Валишева, А.А. Гузев, В.М. Ефимов, А.П. Ковчавцев, Г.Л. Курышев, В.Г. Половинкин. Прикл. физика, № 2, 68 (2007).

[54] В.И. Иванов-Омский, Б.А. Матвеев. ФТП, 41 (3), 257 (2007).

[55] С.Е. Александров, Г.А. Гаврилов, Б.А. Матвеев, М.А. Ременный, Г.Ю. Сотникова. Патент РФ № 2610073 от 07.022017 г. (Заявка на изобретение \# 2013109254 от 01.03.2013).

[56] M. Tavakoli, L. Turicchia, R. Sarpeshkar. IEEE Trans. Biomed. Circ. Syst., 4 (1), 27 (2010).

[57] R.G. Haahr, S.B. Duun, M.H. Toft, B. Belhage, J. Larsen, K. Birkelund, E.V. Thomsen. IEEE Trans. Biomed. Circ. Syst., 6, 45 (2012).

[58] M.A. Remennyi, N.V. Zotova, S.A. Karandashev, B.A. Matveev, N.M. Stus', G.N. Talalakin. Sensors Actuators B: Chemical, $91(1-3), 256$ (2003).

[59] В.П. Астахов, Ю.А. Данилов, В.Ф. Дудкин, В.П. Лесников, Г.Ю. Сидорова, Л.А. Суслов, И.И. Таубкин, Ю.М. Эскин. Письма ЖТФ, 18 (3), 1 (1992).

[60] А.В. Любченко, А.В. Сукач, Г.С. Олейник, Г.П. Нужная, С.А. Сыпко, В.В. Тетеркин, А.В. Фомин, Л.Г. Шепель. Оптоэлектроника и полупроводниковая техника, № 34, 100 (1999). ISSN 0233-7577.

Редактор Л.В. Шаронова

\section{Sources of spontaneous emission based on indium arsenide (overview: 10 years after)}

S.A. Karandashev ${ }^{1}$, B.A. Matveev ${ }^{1}$, M.A. Remennyi ${ }^{1,2}$

${ }^{1}$ loffe Institute,

194021 St. Petersburg, Russia

${ }^{2}$ IoffeLED, Ltd.,

194064 St. Petersburg, Russia 